Proceedings

\title{
Analysis of Cross-Species Usability of Microsatellite Markers for Baikal Endemic Sponges
}

\author{
Alena Yakhnenko ${ }^{1,2, *}$ and Valeria Itskovich ${ }^{1}$ \\ 1 Limnological Institute, Siberian Branch of the Russian Academy of Sciences, 3, Ulan-Batorskaya, \\ Irkutsk 664033, Russia; info@lin.irk.ru \\ 2 International Intergovernmental Organization Joint Institute for Nuclear Research, 6 Joliot-Curie St, Dubna, \\ 141980, Russia \\ * Correspondence: yakhnenkoas@gmail.com; Tel.: +7-999-420-45-08
}

Citation: Yakhnenko, A.; Itskovich, V. Analysis of Cross-Species Usability of Microsatellite Markers for Baikal Endemic Sponges. 2021, 68, x. https://doi.org/10.3390/xxxxx

Received: date Accepted: date Published: date

Publisher's Note: MDPI stays neutral with regard to jurisdictional claims in published maps and institutional affiliations.

\section{Copyright: $₫ 2021$ by the authors.} Submitted for possible open access publication under the terms and conditions of the Creative Commons Attribution (CC BY) license (http://creativecommons.org/licenses/by/4.0/).

\begin{abstract}
In the last decade, events of mass disease and mortality of sponges have been observed on Lake Baikal, which indicates an ecological crisis on the Lake. Based on the crucial role of sponges as filter feeders and bioindicators, their comprehensive study in this situation is of great interest. Despite the presence of genomic and transcriptome data for several species of endemic Baikal sponges, their population structure has never been studied before. The analysis of the population structure of both marine and freshwater sponges is successfully carried out using microsatellite markers. For freshwater sponges, the only species for which microsatellite markers have been published is Ephydatia fluviatilis, a close relative of the Baikal endemic sponges. Microsatellite markers show a high percentage of interspecies cross-specificity among invertebrates. According to this, we attempted here to assess the suitability of these microsatellite markers for population genetic studies of endemic Baikal sponge Lubomirskia baikalensis based on genomic data. The presence of microsatellite sequence markers homologous to the flanking regions in the L.baikalensis genome was shown for $63.6 \%$ of markers, $71.4 \%$ of which contained microsatellite sequences. However, all of these markers require the development of species-specific primer pairs.
\end{abstract}

Keywords: genetic markers development; microsatellites; sponges

\section{Introduction}

Sponges are one of the oldest multicellular organisms capable of biomineralization. Among the freshwater sponges, there are cosmopolitan and endemic families. One of these families - the Lubomirskiidae - inhabits the unique ancient Lake Baikal. A bouquet of species of endemic sponges has formed in Lake Baikal for the last 2-4 Ma [1-5]. Baikal sponges have high morphological plasticity [6-8] and a reduced rate of evolution of mitochondrial COI $[2,4,9]$ gene, which is commonly used as a barcode for species identification. These factors not only complicate the species identification, but can also indicate unfinished speciation processes. Despite the availability of published genomic data for Lubomirskia baikalensis [10], the population structure of this species has not been studied before. However, such a study is of great interest, since it is not known whether the sponges living in different basins of the lake make up different populations, how the loss of the ability to form gemmules affected the population structure compared to cosmopolitan freshwater sponges [11,12]; did the mass diseases and mortality of sponges observed in Baikal over the last decade [13-18] affected on the structure of populations in mostly diseased areas.

To solve these questions, it is necessary to select molecular genetic markers suitable for population analysis. Microsatellite markers have been successfully used for marine and cosmopolitan freshwater sponges [11,12,19-22] these are short tandem repeats with higher evolutionary rates than other regions of the genome. Several approaches can be 
used to develop microsatellite markers. Testing previously developed markers for a closely related species, or developing markers de novo. Since cross-species specificity testing of microsatellite markers shows good results for invertebrates [23], here we tried to test the suitability of microsatellite markers developed for E.fluviatilis on the Baikal endemic sponge L.baikalensis using bioinformatics methods based on draft genome data and using standard laboratory tests.

\section{Experiments}

Data analysis

To study the suitability of E.fluviatilis microsatellite markers for population genetic analysis of the Baikal endemic sponges of the L.baikalensis species, we searched for flanking regions of microsatellite markers in the L.baikalensis draft genome [10]. The search for flanking sequences of microsatellite markers (left and right separately) was carried out using the BLAST + software package [24] for matches more than 25 base pairs, aligned sequences plus 500 base pairs on each side were extracted using the SeqinR package in the programming language $\mathrm{R}$. The obtained sequences for both species were aligned to the original microsatellite sequence with flanking regions of E.fluviatilis [25] and to the primer sequences for them using the BioEdit 7.0 software package [26] and the MAFFT v 7 online service [27].

DNA isolation, PCR, electrophoresis

Total DNA was isolated using the CTAB method (Gustincich et al., 1991). PCR was carried out using a Techne TC 5000 thermal cycler (UK) using the Encyclo Plus PCR kit (Eurogen, Russia). PCR products were visualized by electrophoresis in $2 \%$ agarose gel for $40 \mathrm{~min}$. For loci that gave clear single bands on the agarose gel, fragment analysis was performed.

\section{Results}

Based on the results of bioinformatic analysis of L.baikalensis genomic data, hits with the flanking regions of the Efl3-Efl22 microsatellite markers were identified and analyzed [25].

Since the published draft genome of the L.baikalensis is incomplete, therefore, in addition to bioinformatics analysis, the cross-species specificity of the Efl3-Efl22 microsatellite markers was also assessed using standard laboratory methods (PCR, gel electrophoresis, fragment analysis). When analyzing the genome, hits were found for seven markers, microsatellite sequences were present only in five of them. For the two markers, more than one hit was found in different regions of the genome.

Each marker Efl3-Efl22 was amplified with three samples of L. baikalensis, and only for two markers out of 11 (Efl7 and Efl20), clear single bands were obtained on gel electrophoresis. The rest of the markers either did not produce a PCR product, or a multiple PCR product was amplified.

According to the results of fragment analysis, the length of the Efl7 locus was 337 base pairs for all three samples. It was not possible to assess the expected length based on the genomic data of L.baikalensis, since no hits was found for this marker. The reason may be the incompleteness of the genome data. The Efl20 locus was 158 bp in all samples, although the expected length based on genomic data is $213 \mathrm{bp}$. The absence of heterozygous individuals and individuals with different alleles among the analyzed samples indicates the unsuitability of these two markers for population genetic studies of L.baikalensis.

We also analyzed the coincidences of the E.fluviatilis primer sequences with similar regions in the L.baikalensis genome. The analysis revealed that the primer pairs published for microsatellite markers for E.fluviatilis (Efl3-Efl22) are not suitable for specific amplification of markers of the Baikal endemic sponges L.baikalensis, since the genome regions containing primer sequences also contain a large number of substitutions. 


\section{Discussion}

According to the data obtained, the presence of homologous flanking regions to microsatellite markers sequence in the L.baikalensis genome was shown for $63.6 \%$ of markers, $71.4 \%$ of which contained microsatellite sequences, namely markers Efl3, Efl4, Efl9, Efl17, Efl20. The obtained values are $10 \%$ lower than the average value of cross species specific microsatellite markers for invertebrates (Barbará et al., 2007),. Despite the presence of microsatellites and hits in the flanking regions of these loci, they all require the development of new specific primer pairs.

\section{Conclusions}

Thus, the microsatellite markers developed and successfully used for population genetic studies for E. fluviatilis [11,12] are not suitable for population genetic studies of endemic Baikal sponges L. baikalensis.

The development of microsatellite markers based on L.baikalensis genomic data is more promising. It is possible that the search for universal microsatellite sequences in the published genomes of freshwater sponges will create a basis for the development of universal microsatellite markers for many closely related species. This work is underway at the moment.

Author Contributions: Y.A. and I.V. conceived and designed the experiments, wrote the paper; Y.A. performed the experiments and analyzed the data, I.V. supervised research. All authors have read and agreed to the published version of the manuscript.

Funding: The reported study was funded by RFBR and the Government of the Irkutsk Region, project number 20-44-383010 and basic funding, project number 0279-2021-0011.

Institutional Review Board Statement: Not applicable.

Informed Consent Statement: Not applicable.

Data Availability Statement: Not applicable.

Conflicts of Interest: The authors declare no conflict of interest. The funding sponsors had no role in the design of the study; in the collection, analyses, or interpretation of data; in the writing of the manuscript, and in the decision to publish the results.

\section{Abbreviations}

The following abbreviations are used in this manuscript: COI: Cytochrome c oxidase subunit I.

\section{References}

1. Efremova, S.M. New Genus and New Species of Sponges from Family Lubomirskiidae Rezvoj, 1936. In Index of Animal Species Inhabiting Lake Baikal and Its Catchment Area; Timoshkin, O.A., Ed.; Nauka: Moscow, Russia, 2004;

2. Itskovich, V.B.; Belikov, S.I.; Efremova, S.M.; Masuda, Y.; Krasko, A.; Schroeder, H.C.; Mueller, W.E.G. Monophyletic origin of freshwater sponges in ancient lakes based on partial structures of COXI gene. Hydrobiologia 2006, 568, 155-159, doi:10.1007/s10750-006-0320-z.

3. Itskovich, V.B.; Gontcharov, A.; Masuda, Y.; Nohno, T.; Belikov, S.; Efremova, S.; Meixner, M.; Janussen, D. Ribosomal ITS sequences allow resolution of freshwater sponge phylogeny with alignments guided by secondary structure prediction. J. Mol. Evol. 2008, 67, 608-620, doi:10.1007/s00239-008-9158-5.

4. Maikova, O.; Khanaev, I.; I Belikov, S.; Sherbakov, D.Y. Two hypotheses of the evolution of endemic sponges in Lake Baikal (Lubomirskiidae). J. Zool. Syst. Evol. Res. 2015, 53, 175-179, doi:10.1111/jzs.12086.

5. Meixner, M.J.; Lüter, C.; Eckert, C.; Itskovich, V.; Janussen, D.; Von Rintelen, T.; Bohne, A.V.; Meixner, J.M.; Hess, W.R. Phylogenetic analysis of freshwater sponges provide evidence for endemism and radiation in ancient lakes. Mol. Phylogenet. Evol. 2007, 45, 875-886, doi:10.1016/j.ympev.2007.09.007.

6. Palumbi, S.R. How body plans limit acclimation: Responses of a demosponge to wave force. Ecology 1986, 67, 208-214 doi:10.2307/1938520.

7. Bell, J.J.; Barnes, D.K.A.; Turner, J.R. The importance of micro and macro morphological variation in the adaptation of a sublittoral demosponge to current extremes. Mar. Biol. 2002, 140, 75-81, doi:10.1007/s002270100665. 
8. Masuda, Y. Studies on the taxonomy and distribution of freshwater sponges in Lake Baikal. Prog. Mol. Subcell. Biol. 2009, 47, 81110, doi:10.1007/978-3-540-88552-8_4.

9. Yakhnenko, A.S.; Itskovich, V.B. Analysis of mtDNA variability in closely related Baikal sponge species for new barcoding marker development. Limnology 2020, 21, 49-57, doi:10.1007/s10201-019-00599-7.

10. Kenny, N.J.; Plese, B.; Riesgo, A.; Itskovich, V.B. Symbiosis, Selection, and Novelty: Freshwater Adaptation in the Unique Sponges of Lake Baikal. Mol. Biol. Evol. 2019, 36, 2462-2480, doi:10.1093/molbev/msz151.

11. Li, R.; Nitsche, F.; Arndt, H. Mesoscale investigations based on microsatellite analysis of the freshwater sponge Ephydatia fluviatilis in the River-Sieg system (Germany) reveal a genetic divergence. Conserv. Genet. 2018, 19, 959-968, doi:10.1007/s10592018-1069-4.

12. Lucentini, L.; Gigliarelli, L.; Puletti, M.E.; Palomba, A.; Caldelli, A.; Fontaneto, D.; Panara, F. Spatially explicit genetic structure in the freshwater sponge Ephydatia fluviatilis (Linnaeus, 1759) within the framework of the monopolisation hypothesis. J. Limnol. 2013, 72, e14, doi:10.4081/jlimnol.2013.e14.

13. Kaluzhnaya, O.V.; Itskovich, V.B. Bleaching of Baikalian Sponge Affects The Taxonomic Composition of Symbiotic Microorganisms. Genetika 2015, 51, 1153-1157, doi:10.7868/s0016675815110077.

14. Itskovich, V.B.; Shigarova, A.; Glyzina, O.; Kaluzhnaya, O.; Borovskii, G. Heat shock protein 70 (Hsp70) response to elevated temperatures in the endemic Baikal sponge Lubomirskia baikalensis. Ecol. Indic. 2018, 88, 1-7, doi:10.1016/j.ecolind.2017.12.055.

15. Belikov, S.; Belkova, N.; Butina, T.; Chernogor, L.; Kley, A.M.-V.; Nalian, A.; Rorex, C.; Khanaev, I.; Maikova, O.; Feranchuk, S. Diversity and shifts of the bacterial community associated with Baikal sponge mass mortalities. PLoS ONE 2019, 14, e0213926, doi:10.1371/journal.pone.0213926.

16. Khanaev, I.V.; Kravtsova, L.S.; Maikova, O.O.; Bukshuk, N.A.; Sakirko, M.V.; Kulakova, N.V.; Butina, T.V.; Nebesnykh, I.A.; Belikov, S.I. Current state of the sponge fauna (Porifera: Lubomirskiidae) of Lake Baikal: Sponge disease and the problem of conservation of diversity. J. Great Lakes Res. 2018, 44, 77-85, doi:10.1016/j.jglr.2017.10.004.

17. Denikina, N.N.; Dzyuba, E.V.; Bel'Kova, N.L.; Khanaev, I.V.; Feranchuk, S.I.; Makarov, M.M.; Granin, N.G.; Belikov, S.I. The first case of disease of the sponge Lubomirskia baicalensis: Investigation of its microbiome. Biol. Bull. 2016, 43, 263-270.

18. Kulakova, N.V.; Sakirko, M.V.; Adelshin, R.V.; Khanaev, I.V.; Nebesnykh, I.A.; Pérez, T. Brown Rot Syndrome and Changes in the Bacterial Community of the Baikal Sponge Lubomirskia baikalensis. Microb. Ecol. Microbial. Ecol. 2018, 75, 1024-1034, doi:10.1007/s00248-017-1097-5.

19. Blanquer, A.; Uriz, M.J. Population genetics at three spatial scales of a rare sponge living in fragmented habitats. BMC Evol. Biol. 2010, 10, doi:10.1186/1471-2148-10-13.

20. Dailianis, T.; Tsigenopoulos, C.S.; Dounas, C.; Voultsiadou, E. Genetic diversity of the imperilled bath sponge Spongia officinalis Linnaeus, 1759 across the Mediterranean Sea: Patterns of population differentiation and implications for taxonomy and conservation. Mol. Ecol. 2011, 20, 3757-3772, doi:10.1111/j.1365-294X.2011.05222.x.

21. Pérez-Portela, R.; Noyer, C.; Becerro, M.A. Genetic structure and diversity of the endangered bath sponge Spongia lamella. Aquat. Conserv. Mar. Freshw. Ecosyst. 2015, 25, 365-379, doi:10.1002/aqc.2423.

22. Riesgo, A.; Taboada, S.; Pérez-Portela, R.; Melis, P.; Xavier, J.R.; Blasco, G.; López-Legentil, S. Genetic diversity, connectivity and gene flow along the distribution of the emblematic Atlanto-Mediterranean sponge Petrosia ficiformis (Haplosclerida, Demospongiae). BMC Evol. Biol. 2019, 19, doi:10.1186/s12862-018-1343-6.

23. Barbará, T.; Palma-Silva, C.; Paggi, G.M.; Bered, F.; Fay, M.F.; Lexer, C. Cross-species transfer of nuclear microsatellite markers: Potential and limitations. Mol. Ecol. 2007, 16, 3759-3767, doi:10.1111/j.1365-294X.2007.03439.x.

24. Camacho, C.; Coulouris, G.; Avagyan, V.; Ma, N.; Papadopoulos, J.S.; Bealer, K.; Madden, T.L. BLAST+: Architecture and applications. BMC Bioinform. 2009, 10, doi:10.1186/1471-2105-10-421.

25. Mol Ecology Resources Primer Molecular Ecology Resources Primer Development Consortium; Anderson, C.M.; Aparicio, G.J.; Atangana, A.R.; Beaulieu, J.; Bruford, M.W.; Cain, F.; Campos, T.; Cariani, A.; Carvalho, M.A.; et al. Permanent Genetic Resources added to Molecular Ecology Resources Database 1 December 2009-31 January 2010. Mol. Ecol. Resour. 2010, 10, 576-579.

26. Hall, T.A. BIOEDIT: A user-friendly biological sequence alignment editor and analysis program for Windows 95/98/ NT. Nucleic Acids Symp. Ser. 1999, 41, 95-98.

27. Katoh, K.; Rozewicki, J.; Yamada, K.D. MAFFT online service: Multiple sequence alignment, interactive sequence choice and visualization. Brief. Bioinform. 2018, 20, 1160-1166, doi:10.1093/bib/bbx108.

28. Gustincich, S.; Manfioletti, G.; Del Sal, G.; Schneider, C.; Carninci, P. A fast method for high-quality genomic DNA extraction from whole human blood. Biotechniques 1991, 41, 95-98. 